\title{
The shortage of benzathine penicillin and its impact on congenital syphilis incidence: an ecologic study in the city of Rio de Janeiro
}

Jose Ueleres Braga ( $\sim$ ueleres@gmail.com )

Escola Nacional de Saude Publica https://orcid.org/0000-0001-5247-007X

Rachel Sarmeiro Araujo

Instituto de Medicina Social, Universidade do Estado do Rio de Janeiro

Ana Sara Semeão de Souza

Instituto de Medicina Social, Universidade do Estado do Rio de Janeiro

Research article

Keywords: Congenital Syphilis, Epidemiological Monitoring, Spatial Analysis

Posted Date: March 28th, 2020

DOI: https://doi.org/10.21203/rs.3.rs-19557/v1

License: (1) (i) This work is licensed under a Creative Commons Attribution 4.0 International License.

Read Full License 


\section{Abstract}

\section{Background}

The Pan American Health Organization indicates that the increased congenital syphilis (CS) incidence can be attributed to (i) the improvement of epidemiological surveillance, (ii) the expansion of rapid diagnostic tests, and (iii) the lack of penicillin. However, there is no scientific evidence to support the impact of the penicillin shortage on the increase in the incidence of CS. This study aimed to analyze the relationship between the benzathine penicillin (BP) shortage and the significant increase in the incidence of congenital syphilis in the city of Rio de Janeiro from 2013 to 2017.

Methods

We used a mixed ecologic study design (temporal and multiple groups). Analysis units were the neighborhoods (spatial) and quarters (temporal) during those years. The study population consisted of CS patients reported to the Brazil Information System of Notifiable Diseases (SINAN) that were living in the city of Rio de Janeiro, which was geocoded by neighborhood. The BP supply measure for use in Gestational Syphilis considered the ratio between two Benzatin Pencil Dispenser bottle quantities: (a) the number of bottles dispensed to health facilities in each neighborhood and (b) the number of bottles necessary to treat pregnant women diagnosed with syphilis and their respective partners residing in each neighborhood. To evaluate the association between shortages and a significant increase in CS incidence, the negative-inflated zero-binomial regression model (Iongitudinal model) was used. Crude and adjusted odds ratios were calculated to express the magnitude of the associations. A theoretical model was proposed with four dimensions: sociodemographic, economic, geographical, and prenatal care. The selection of adjustment variables was considered using Directed Acyclic Graphs.

Results

During the study period, the incidence rate of CS in Rio de Janeiro neighborhoods was on average $19.6 / 1000$ live births. In the simple analysis, shortage was associated with a 2.17 -fold increase in the risk of a significant increase in CS incidence. After adjustment for the sufficient minimum set, the strength of association increased to 2.23 (95\% confidence interval, 1.15-4.30).

Conclusions

We conclude that the benzathine penicillin shortage impacted the increase in the incidence of congenital syphilis in Rio de Janeiro.

\section{Background}

The World Health Organization (WHO) estimates that there are 5.6 million new cases of syphilis annually and 18 million prevalent cases ${ }^{1}$. In 2012, the WHO estimated that there were approximately 930,000 pregnant women with active syphilis, resulting in 350,000 adverse birth outcomes ${ }^{2}$. 
Vertical transmission of syphilis during pregnancy can lead to severe fetal outcomes in the second or third trimester, including early fetal death, stillbirth, neonatal death, premature birth, low birth weight, and congenital infection ${ }^{3}$. Syphilis is the second infectious cause of stillbirths worldwide and an important preventable contributor to infant morbidity and mortality ${ }^{3,4}$.

Benzathine penicillin (BP) is the only treatment recommended to prevent vertical transmission of syphilis. A single dose of low-cost BP terminates syphilis infectivity with no documented risk of antibiotic resistance. Treating pregnant women infected with syphilis at least 28 days before delivery can reduce the risk of stillbirth and neonatal mortality by $82 \%$ and $80 \%$, respectively 5 .

According to the WHO, the incidence rate of global Congenital Syphilis (CS) decreased between 2012 and 2016, falling from 5.4 cases per 1,000 live births to 4.76. In Brazil, the CS incidence rate has been increasing in recent years; between 2010 and 2017, the disease incidence rate increased 3.6 times, from 2.4 to 8.6 cases per 1,000 live births ${ }^{1}$. Moreover, in 2017 , the state of Rio de Janeiro had syphilis detection rates in pregnant women and CS incidence much higher than the national average -35.6 and 18.8 cases per 1,000 live births, respectively ${ }^{6}$.

According to the Pan American Health Organization report, the increased CS incidence can be attributed to epidemiological surveillance system improvements, the expansion of rapid diagnostic test distribution, the lack of penicillin, and the fact that almost half of primary health care units do not treat patients but refer them to other levels of care with subsequent loss of patients during the referral process ${ }^{7}$. However, there is no scientific evidence to support the possible impact of penicillin shortages on the significant increase in CS incidence. Knowing the relationship between the lack of BP and the increased CS incidence can be a challenging task, given the existence of several individuals and contextual factors that can contribute to this increase. To address this challenge, the use of causal diagrams to assist in the interpretation of epidemiological relationships has recently been suggested. Since diagrams represent causal rather than merely associative links, they lend themselves to the analysis of confounding factors and selection effects, identifying variables that must be measured and controlled to obtain unobtrusive effects estimates ${ }^{8}$.

Drug shortages are known to be one of the obstacles to accessing timely and appropriate treatment of preventable diseases such as syphilis. Thus, identifying the possible impact of the BP shortage on the increase of CS can generate useful information for planning actions aimed at controlling this disease. This article aims to analyze the relationship between the BP shortage and the significant increase in CS incidence in the city of Rio de Janeiro, Brazil from 2013 to 2017.

\section{Methods}

We used a mixed ecologic study design (temporal and multiple groups). Analysis units were the neighborhoods (geographic) and quarters (temporal) during the study years. The study population consisted of CS cases reported to the Brazil Information System of Notifiable Diseases (SINAN) during 
2013-2017 for those living in the city of Rio de Janeiro, which was geocoded by neighborhood. Only municipal health units $(\mathrm{HU})$ patients were included in the study (i.e., notifications from federal/state units and private/psychiatric hospitals were excluded).

The geographical units of study were 160 geocoded neighborhoods in SINAN (Fig. 1). Four data sources were used: (i) SINAN's Gestational Syphilis and Congenital Syphilis registry databases, (ii) reports and spreadsheets on the dispensation of BP provided by the Pharmaceutical Assistance Center of the Municipal Health Secretariat (SMS-Rio), (iii) population data of the census tracts and neighborhoods of the 2010 Census of the Brazilian Institute of Geography and Statistics, and (iv) live birth registry data from the Live Birth Information System of the municipality of Rio de Janeiro.

The disease incidence rate was estimated by dividing the number of CS cases reported in children < 1 year of age by 1,000 live births per trimester in the city of Rio de Janeiro. The study outcome was the significantly increasing incidence rate of CS in Rio de Janeiro, considering the relative difference in the incidence rate of the previous quarter compared with that in the index quarter under analysis.

The significant increase in CS incidence was estimated, as the quarterly rate variation was greater than $200 \%$ (estimated percentage considering 2 times the value of the CS incidence compared with the previous quarter). The outcome was classified as dichotomous (yes/no).

The BP supply measure for use in Gestational Syphilis considered the ratio between two Benzatin Pencil Dispenser bottle quantities: (a) the number of bottles dispensed to health facilities in each neighborhood and (b) the number of bottles necessary to treat pregnant women diagnosed with syphilis and their respective partners residing in each neighborhood.

The BP Dispensation data for the HU in each neighborhood of the city of Rio de Janeiro were extracted from electronic spreadsheets provided by SMS-Rio, where there were three ways the number of BP vials were dispensed: (1) for the HU of each neighborhood, (2) to the General Coordinators of Primary Care of the Program Area (CAP) with their respective neighborhoods, and (3) to both the $\mathrm{HU}$ in specific neighborhoods and to coordinate the program area of the same coverage area.

To obtain the number of vials dispensed to the $\mathrm{HU}$ of each neighborhood, the following estimates were made according to the type of data: (1) for type 1 data, the sum of the number of vials dispensed to the $\mathrm{HU}$ of each neighborhood; (2) for type 2 data, the number of vials distributed to each $\mathrm{HU}$ in the neighborhoods was first estimated based on the number of notifications of Gestational Syphilis in these units, and then the number of vials in the $\mathrm{HU}$ of each neighborhood was summed; and (3) for type 3 data, a combination of the two previous methods was used.

Since not all of the BP that arrived at the HU was used to treat Gestational Syphilis, we assumed that $80 \%$ was used to treat pregnant women with syphilis and their partners. This assumption is justified by two factors: (i) BP is used to treat other infections also prevalent in the HU, such as rheumatic fever, upper respiratory tract infections, soft tissue infections (erysipelas, impetigo), pneumonia, and penicillin- 
sensitive Streptococcus pneumoniae; (ii) in order to stop the growth of CS cases, SMS-Rio prioritized using BP to treat pregnant women with syphilis.

To determine the amount of BP vials needed to treat pregnant women and their partners, the dosage of each individual treatment was considered. In the absence of available data on the clinical classification (staging) of the disease, the therapeutic regimen with three doses of BP was considered, with each dose using two vials of BP $(1,200,000 \mathrm{IU})$, which is six vials used $(7,200,000 \mathrm{IU})$ for the treatment of pregnant women.

The calculation for the number of BP vials needed to treat the pregnant women with reported CS was: the total number of reported cases of gestational syphilis in the $\mathrm{HU}$ of each neighborhood times 6 , plus the $100 \%$ scenario of treated partners, where the scheme was used with three doses. Once obtained from the estimates of the number of dispensed and needed bottles, the supply measure used in this study was calculated by the following formula:

$$
B P S_{i}=\frac{X_{i}}{Y_{i}}
$$

BPS $_{i}$ - benzathine penicillin supply indicator of the neighborhood $i$;

$X_{i}-$ Number of benzathine penicillin vials dispensed (and used) for treatment of Gestational Syphilis and partners in the neighborhood $i$

$Y_{i}-$ Number of vials of benzathine penicillin needed to treat pregnant women and partners in neighborhood $\mathrm{i}$.

The benzathine penicillin supply indicator (BPS) was calculated by quarter, as it was observed that the dispensation did not occur regularly throughout the year. Thus, the quarter was considered as a time unit because it represents the homogeneous dispensation of BP.

As the indicator of supply is a ratio whose values range from 0 to $\infty$, when BPS had a value between 0 and 0.99, it was considered a shortage (yes), and there was no shortage (no) when BPS was greater or equal 1.

In this paper, we use a theoretical model design based on the studies by Kilmarx et al. $(1997)^{9}$ and Thomas et al. (1999) ${ }^{10}$, which aimed to evaluate community factors that influence the incidence of syphilis. Thomas et al. (1999) ${ }^{10}$ found that factors affecting syphilis transmission can be categorized into those acting at the individual level (e.g., number of sexual partners) or at the socio-physical level, such as availability of treatment services for curable infections. In the model created by Thomas et al. 
$(1999)^{10}$, three categories of the socio-physical environment were considered: geographical, architectural, and technological and sociocultural.

Based on this information, the theoretical model used was proposed in four dimensions: sociodemographic, economic, geographical, and prenatal care. Sociodemographic information on the neighborhood populations used included (i) the proportion of women who had children under the age of 20 , (ii) the rate of live births, and (iii) the illiteracy rate in the population over 18 . In the economic dimension, information covered (iv) the proportion of people living in extreme poverty, (v) the Gini coefficient, and (vi) the unemployment rate. The (vii) homicide rate in the neighborhoods and (viii) proportion of the population living in subnormal clusters was also studied in the geographical dimension. Regarding the prenatal care characteristics of the population, we used (ix) the proportion of pregnant women with a non-treponemal test performed, $(x)$ the proportion of women who had more than six prenatal consultations during their pregnancy, and the (xi) proportion of treated partners.

To evaluate the association between the BP shortage and a significant increase in CS incidence, the negative-inflated zero-binomial regression model (longitudinal model) was used. Crude and adjusted odds ratios were calculated to express the magnitude of the studied associations. The selection of adjustment variables was considered using Directed Acyclic Graphs (DAG). Figure 2 shows the relationships between covariates, exposure, and outcome. This approach also involved the strategy of identifying the minimum set of variables necessary to obtain the adjusted measurements.

\section{Results}

The CS incidence rate in neighborhoods in the municipality of Rio de Janeiro during the study period was on average 19.6 cases per 1,000 live births; however, this measure varied between neighborhoods. In some, the incidence rate was 0 , and in others, it reached 400 cases per 1,000 live births (Table 1). The significant increase in the incidence of congenital syphilis was observed in $4 \%$ of the neighborhoods (quarter-years) during the study period.

The distribution of the incidence of CS and its significant increase in the neighborhoods indicates heterogeneity and concentration of higher rates in the central-north and west regions (Fig. 3). The Anil and Tanque neighborhoods had the highest number of quarter-years with an increase in incidence greater than $200 \%$ during the study period, both located in the northern part of the municipality (Fig. 3b).

Besides, the average BP supply level was 0.81 during the study period. This value represents that, on average, there was a shortage of BP in the neighborhoods of the municipality of Rio de Janeiro in the period from 2013 to 2017 (Table 1). Regarding the sociodemographic characteristics of neighborhoods in the city of Rio de Janeiro, on average, the rate of live births was 2.7 per 1,000 inhabitants, $3 \%$ of the population was illiterate, and $14 \%$ of the live births recorded were to women under 20 years old.

In the economic dimension, neighborhoods in the municipality of Rio de Janeiro had an average Gini coefficient of 0.44 and $10.4 \%$ of the population living in extreme poverty. As for the characteristics of 
prenatal care, on average, $76 \%$ of pregnant women had 7 or more prenatal consultations, $60 \%$ had their partners treated for syphilis, and 39\% underwent the non-treponemal test during prenatal care (Table 1). Finally, concerning the geographical dimension, the neighborhoods in the municipality of Rio de Janeiro had an average homicide rate of 87.5 per 100,000 inhabitants, and $21.55 \%$ of its population lived in subnormal agglomerations during the study period. 
- Distribution of variables in the study population, Rio de Janeiro 2013-2017

\begin{tabular}{|c|c|c|c|c|}
\hline Variables & $\mathbf{N}$ & Average & $\begin{array}{l}\text { Standard } \\
\text { deviation }\end{array}$ & $\begin{array}{l}\text { (min- } \\
\text { max.) }\end{array}$ \\
\hline Congenital Syphilis incidence & 3166 & 19.60 & 25.92 & $\begin{array}{l}(0- \\
400)\end{array}$ \\
\hline Greater than $200 \%$ in Congenital Syphilis incidence & 3040 & 0.04 & 0.20 & $(0-1)$ \\
\hline Benzathine Penicillin supply & 2201 & 0.81 & 0.39 & $(0-1)$ \\
\hline \multicolumn{5}{|l|}{ Sociodemographic } \\
\hline Birth rate & 3200 & 2.7 & 3.48 & $\begin{array}{l}(0.003- \\
26.56)\end{array}$ \\
\hline Illiteracy rate in the population over 18 & 3200 & 3.29 & 1.80 & $\begin{array}{l}(0.12- \\
9.87)\end{array}$ \\
\hline $\begin{array}{l}\text { Proportion of births to women who were under the age of } \\
20\end{array}$ & 3200 & 14.0 & 0.06 & $\begin{array}{l}(0- \\
27.0)\end{array}$ \\
\hline \multicolumn{5}{|l|}{ Economic } \\
\hline Gini coefficient & 3200 & 0.44 & 0.03 & $\begin{array}{l}(0.37- \\
0.54)\end{array}$ \\
\hline Proportion of people living in extreme poverty & 3200 & 10.41 & 6.44 & $\begin{array}{l}(0- \\
29.55)\end{array}$ \\
\hline \multicolumn{5}{|l|}{ Prenatal care } \\
\hline $\begin{array}{l}\text { Proportion of women who had more than six prenatal } \\
\text { consultations during pregnancy }\end{array}$ & 3200 & 76.0 & 0.08 & $\begin{array}{l}(57.0- \\
93.0)\end{array}$ \\
\hline Proportion of treated partners & 3200 & 60.0 & 0.23 & $\begin{array}{l}(0- \\
100)\end{array}$ \\
\hline $\begin{array}{l}\text { Proportion of pregnant women with a non-treponemal } \\
\text { test performed }\end{array}$ & 3200 & 39.0 & 0.18 & $\begin{array}{l}(0- \\
100)\end{array}$ \\
\hline \multicolumn{5}{|l|}{ Geographical } \\
\hline Proportion of the population living in subnormal clusters & 3200 & 21.55 & 22.48 & $\begin{array}{l}(0- \\
100)\end{array}$ \\
\hline Homicide rate & 3140 & 87.48 & 59.14 & $\begin{array}{l}(0- \\
404.33)\end{array}$ \\
\hline
\end{tabular}

Table 2 shows the crude and adjusted prevalence ratios considering the minimum adjustment sufficient to estimate the direct effect of BP shortage and the significant increase in CS incidence. Considering the causal relationships between the covariates, exposure, and outcome, DAG provided four minimum sets sufficient to estimate the direct effect between BP shortages and the significant increase in CS. 
In the simple analysis, shortage was associated with a 2.17 -fold increase in the risk of a significant increase in the CS incidence rate in the neighborhoods per quarter-year (Table 2). After adjusting for the first sufficient minimum set (model 1), the strength of association increased to $2.23(95 \% \mathrm{Cl}, 1.15-4.30)$. In the second adjusted model, the probability of a significant increase in CS incidence was $2.20(95 \% \mathrm{Cl}$, 1.14-4.24). The third and fourth models presented a risk of a significant increase in the CS incidence of 2.19 (95\% Cl, 1.14-4.23) (Table 2). After adjusting for all of the minimum sets sufficient to estimate the direct effect, it was observed that model 1, with the lowest AIC (764.76), had the best fit.

Table 2

- Crude and adjusted longitudinal models, considering the minimum adjustment sufficient to estimate the direct effect of shortages and the significant increase of congenital syphilis incidence

\begin{tabular}{|c|c|c|c|c|c|}
\hline Models & $\mathrm{OR}^{\mathrm{c}}$ & $\begin{array}{l}95 \% \\
\mathrm{Cl}\end{array}$ & $\mathrm{OR}^{\mathrm{a}}$ & $\begin{array}{l}95 \% \\
\mathrm{Cl}\end{array}$ & AlC \\
\hline Benzathine Penicillin supply & 2.17 & $\begin{array}{l}(1.13- \\
4.18)\end{array}$ & & & 771,03 \\
\hline $\begin{array}{l}\text { Model } 1 \text { (BP supply }+ \text { non-treponemal test }+\geq 7 \\
\text { prenatal consultations }+ \text { treated partners }+ \text { people living } \\
\text { in extreme poverty }+ \text { Gini) }\end{array}$ & & & 2.23 & $\begin{array}{l}(1.15- \\
4.30)\end{array}$ & 764.76 \\
\hline $\begin{array}{l}\text { Model } 2 \text { (BP supply + non-treponemal test + births to } \\
\text { women < } 20 \text { y + treated partners + people living in } \\
\text { extreme poverty) }\end{array}$ & & & 2.20 & $\begin{array}{l}(1.14- \\
4.24)\end{array}$ & 767.11 \\
\hline $\begin{array}{l}\text { Model } 3 \text { (BP supply + non-treponemal test + treated } \\
\text { partners + people living in extreme poverty + Illiteracy } \\
\text { rate }>18 \text { y) }\end{array}$ & & & 2.19 & $\begin{array}{l}(1.14- \\
4.23)\end{array}$ & 766.73 \\
\hline $\begin{array}{l}\text { Model } 4 \text { (BP supply }+ \text { non-treponemal test }+ \text { treated } \\
\text { partners + population living in subnormal clusters }+ \\
\text { Illiteracy rate }>18 \mathrm{y} \text { ) }\end{array}$ & & & 2.19 & $\begin{array}{l}(1.14- \\
4.23)\end{array}$ & 776.49 \\
\hline
\end{tabular}

\section{Discussion}

The incidence rate of CS was an average of 19.6 cases per 1,000 live births in neighborhoods in the municipality of Rio de Janeiro during the study period, a value greater than 40 times the WHO goal of eliminating $\mathrm{CS}^{11}$. Moreover, our study found that $4 \%$ of the neighborhoods showed a $200 \%$ increase in CS incidence in the quarter under analysis compared with the previous quarter. Another important finding was that the BP shortage in the city of Rio de Janeiro between 2013 and 2017 was directly related to the significant increase in CS incidence. Adjusting for factors related to prenatal care and economic conditions increased the strength of the association between BP shortages and increased CS.

A study by Reis et al. ${ }^{12}$ pointed out an average of 17.3 cases $/ 1,000$ live births as the CS incidence rate from 2011 to 2014 in the neighborhoods of Rio de Janeiro. This finding is in line with what was estimated in our study, which points to an average increase in the incidence of CS over time. Additionally, 
the analysis of CS in neighborhoods in the city of Rio de Janeiro showed the proportion of live births, wherein the mothers had seven or more prenatal care consultations, as an important component to explain the problem ${ }^{12}$. It is a variable that expresses the importance of continuity of care, a central feature of primary health care in the detection and treatment of infected pregnant women, as well as their sexual partners, in addition to monitoring possible reinfections and preventing vertical transmission of syphilis $^{12,13}$.

The study by Silveira et al. ${ }^{14}$ assessed the success of and problems in the elimination of CS in Latin America and the Caribbean. The study revealed that the main challenges to the elimination of CS concerned improvements in the areas of prenatal care and coverage of syphilis tests; training of health professionals in diagnosis, treatment, and monitoring of syphilis (including that of newborns and sexual contacts of infected mothers); availability of rapid tests for syphilis; and BP for timely and appropriate treatment of pregnant women and their partners ${ }^{14}$.

According to the WHO, between 2014 and 2016, 39 countries reported a BP shortage. Of these, five belong to Latin America (Brazil, Jamaica, Panama, Suriname, and Trinidad and Tobago) ${ }^{15}$. In July 2015, BP was completely out-of-stock for almost half of the Brazilian states, and in $11(41 \%)$, the vast majority of the North and Northeast regions, the stock had been indicated as zero. In the other areas, however, some shortages were reported, with the state of Rio de Janeiro being among them ${ }^{16}$.

In Brazil, syphilis has the highest rates of vertical transmission among the various diseases that can be transmitted during the pregnant-puerperal cycle $e^{1,17}$. In 2012, the vertical transmission rate was estimated at $34.3 \%{ }^{18}$. Local studies have found vertical transmission rates ranging from $21.1-100 \% 18,19,20$. Despite the fact that vertical transmission of syphilis has different intensities according to the stage of the maternal disease, it is known that appropriate treatment with penicillin can prevent $97 \%$ of vertical transmission cases $^{5}$. As seen in our study, the lack of medication has a potentiated effect on the control of CS, even when considering the difficulties of covering syphilis screening during pregnancy and adhering to the treatment of pregnant women and their partners.

Despite improved diagnostic testing options for pregnant women and their partners with the introduction of rapid tests, the rate of vertical transmission of syphilis has not declined as expected, which shows that diagnosis alone is not enough to guarantee a quality improvement of care for pregnant women with syphilis $^{21}$.

Another relevant factor is the characteristics of the population most affected in vertical transmission of CS. A study carried out in six Brazilian states found that the occurrence of CS affected more women with less than eight years of schooling, black women (black and mixed-race), and residents of the capitals ${ }^{21}$. Almost $70 \%$ of these women had undergone prenatal care, but most of them were only diagnosed with syphilis at the time of delivery, thus causing inadequate maternal treatment ${ }^{21}$. 
The higher prevalence of syphilis during pregnancy in women of low socioeconomic status, with obstetric risk, and worse access to health services ${ }^{18}$, indicates the greater social and reproductive vulnerability of these women, making the challenge of controlling syphilis in this population even more complex.

Screening for syphilis during pregnancy is one of the most cost-effective activities in public health; however, increasing syphilis screening during antenatal care to achieve elimination goals will involve increased demand for $\mathrm{BP}^{22,23}$. In 2016, Taylor et al. ${ }^{22}$ estimated the need for BP to treat women diagnosed with syphilis in order to manage the CS epidemic in countries with a high disease burden. The results of this study suggest a number twice as high as the amount expected annually for these countries if the WHO recommendations for the elimination of CS are adopted, reaching at least $95 \%$ of the coverage for syphilis screening.

\section{Conclusions}

Although syphilis is a disease for which simple and low-cost diagnostic and therapeutic resources exist, its control during pregnancy proves to be a challenge for health professionals and managers. This is due to (i) the short interval of pregnancy, which limits the time for diagnosis and treatment; (ii) the difficulty in approaching sexually transmitted diseases, especially during pregnancy; and (iii) the lack of knowledge of the magnitude of this condition and the damage it can cause to the health of women and babies within the population ${ }^{18}$.

This study allows us to conclude that the shortage of benzathine penicillin impacted the increase in the incidence of congenital syphilis in Rio de Janeiro between 2013 and 2017.

\section{Abbreviations}

CS: Congenital Syphilis; BP: Benzathine Penicillin; SINAN: Brazil Information System of Notifiable Diseases; WHO: World Health Organization; HU: Health Units; SMS-Rio: Municipal Health Secretariat; CAP: General Coordinators of Primary Care of the Program Area; BPS: Benzathine Penicillin Supply Indicator; DAG: Directed Acyclic Graphs.

\section{Declarations}

\section{Ethics approval and consent to participate}

The study project was submitted and approved by the Research Ethics Committee (CEP) of the Health Secretariat of the Municipality of Rio de Janeiro SMS-Rio (CAAE: 06019018.3.3001.5279).

Consent for publication

Not applicable 
Data on notification of diseases under surveillance in Brazil are provided upon written request to the Ministry of Health and with specific use for the scientific investigation declared in the application (PORTARIA Nº 66, DE 10 DE DEZEMBRO DE 2004).

\section{Competing interests}

The authors declare that they have no competing interests

\section{Funding}

This study was financed in part by the Coordenação de Aperfeiçoamento de Pessoal de Nível Superior Brasil (CAPES).

\section{Authors' contributions}

All authors contributed to the proposal development and write-up of the research. All authors assisted in data interpretation, critical review of the manuscript and approved the final version of the manuscript.

\section{Acknowledgments}

Not applicable.

\section{References}

1. Wijesooriya NS, Rochat RW, Kamb ML, Turlapati P, Temmerman M, Broutet N, et al. Global burden of maternal and congenital syphilis in 2008 and 2012: a health systems modelling study. Lancet Glob Health. 2016;4(8):e525-33. Epub 2016/07/23. doi: 10.1016/s2214-109x(16)30135-8.

2. Newman L, Rowley J, Vander Hoorn S, Wijesooriya NS, Unemo M, Low N, et al. Global Estimates of the Prevalence and Incidence of Four Curable Sexually Transmitted Infections in 2012 Based on Systematic Review and Global Reporting. PLoS One. 2015;10(12):e0143304. Epub 2015/12/10. doi: 10.1371/journal.pone.0143304.

3. Gomez GB, Kamb ML, Newman LM, Mark J, Broutet N, Hawkes SJ. Untreated maternal syphilis and adverse outcomes of pregnancy: a systematic review and meta-analysis. Bull World Health Organ. 2013;91(3):217-26. Epub 2013/03/12. doi: 10.2471/blt.12.107623.

4. Lawn JE, Blencowe $H$, Waiswa $P$, Amouzou A, Mathers $C$, Hogan D, et al. Stillbirths: rates, risk factors, and acceleration towards 2030. Lancet. 2016;387(10018):587-603. Epub 2016/01/23. doi: 10.1016/s0140-6736(15)00837-5.

5. Blencowe H, Cousens S, Kamb M, Berman S, Lawn JE. Lives Saved Tool supplement detection and treatment of syphilis in pregnancy to reduce syphilis related stillbirths and neonatal mortality. BMC Public Health. 2011;11 Suppl 3:S9. Epub 2011/04/29. doi: 10.1186/1471-2458-11-s3-s9.

6. Brasil. Ministério da Saúde. Secretaria de Vigilância em Saúde. Boletim Epidemiológico de Síflis. Vol 49, nº 45, 2018. Brasília: Ministério da Saúde; 2017. Available from: http://www.aids.gov.br/pt- 
br/pub/2018/boletim-epidemiologico-de-sifilis-2018

7. Pan American Health Organization. Elimination of mother-to-child transmission of HIV and syphilis in the Americas. Update 2016. Washington DC: PAHO, 2017. Available from:

http://iris.paho.org/xmlui/bitstream/handle/123456789/34072/9789275119556-eng.pdf

8. Joffe M, Mindell J. Complex causal process diagrams for analyzing the health impacts of policy interventions. Am J Public Health. 2006;96(3):473-9. Epub 2006/02/02. doi:

10.2105/ajph.2005.063693.

9. Kilmarx PH, Zaidi AA, Thomas JC, Nakashima AK, St Louis ME, Flock ML, et al. Sociodemographic factors and the variation in syphilis rates among US counties, 1984 through 1993: an ecological analysis. Am J Public Health. 1997;87(12):1937-43. doi: 10.2105/ajph.87.12.1937.

10. Thomas JC, Clark M, Robinson J, Monnett M, Kilmarx PH, Peterman TA. The social ecology of syphilis. Soc Sci Med. 1999;48(8):1081-94. Epub 1999/07/02. doi: 10.1016/s0277-9536(98)00408-0.

11. World Health Organization. The global elimination of congenital syphilis: rationale and strategy for action. Geneva: WHO, 2007. Available from: https://apps.who.int/iris/handle/10665/43782

12. Reis GJd, Barcellos C, Pedroso MdM, Xavier DR. Diferenciais intraurbanos da síflis congênita: análise preditiva por bairros do Município do Rio de Janeiro, Brasil. Cadernos de Saúde Pública. 2018; 34(9): e00105517. Epub Sep 06, 2018. http://dx.doi.org/10.1590/0102-311x00105517.

13. Cunha EMd, Giovanella L. Longitudinalidade/continuidade do cuidado: identificando dimensões e variáveis para a avaliação da Atenção Primária no contexto do sistema público de saúde brasileiro. Ciência \& Saúde Coletiva. 2011; 16(Suppl 1): 1029-1042. http://dx.doi.org/10.1590/S141381232011000700036.

14. Silveira MF, de Leon RGP, Becerra F, Serruya SJ. Evolution towards the elimination of congenital syphilis in Latin America and the Caribbean: a multicountry analysis. Rev Panam Salud Publica. 2019 Mar 15;43:e31. doi: 10.26633/RPSP.2019.31.

15. Nurse-Findlay S, Taylor MM, Savage M, Mello MB, Saliyou S, Lavayen M, et al. Shortages of benzathine penicillin for prevention of mother-to-child transmission of syphilis: An evaluation from multi-country surveys and stakeholder interviews. PLoS Med. 2017;14(12):e1002473. Epub 2017/12/28. doi: 10.1371/journal.pmed.1002473.

16. Brasil. Ministério da Saúde. Secretaria de Vigilância em Saúde e Secretaria de Atenção à Saúde. Situação Atual da Sífllis no Brasil e de Penicilina Benzatina para prevenção da Síflis Congênita Brasília: Ministério da Saúde, 2015. Available from: https://www2.camara.leg.br/atividadelegislativa/comissoes/comissoes-permanentes/cssf/audiencias-publicas/audiencia-publica2015/audiencia-29.09/apresentacao-adeli17. Ramos Jr. AN, Matida LH, Saraceni V, Veras MAdSM, Pontes RJS. Control of mother-to-child transmission of infectious diseases in Brazil: progress in HIV/AIDS and failure in congenital syphilis. Cadernos de Saúde Pública. 2007; 23(Suppl 3): S370-S378. http://dx.doi.org/10.1590/S0102-311X2007001500005.

17. Domingues RMSM, Saracen V, Hartz ZMDA, Leal MDC. Sífilis congênita: evento sentinela da qualidade da assistência pré-natal. Revista de Saúde Pública. 2013 Feb; 47(1): 147-157. 
http://dx.doi.org/10.1590/S0034-89102013000100019.

18. Oliveira LRd, Costa MdCN, Barreto FR, Pereira SM, Dourado I, Teixeira MG. Evaluation of preventative and control measures for congenital syphilis in State of Mato Grosso. Revista da Sociedade Brasileira de Medicina Tropical. 2014 June; 47( 3 ): 334-340. http://dx.doi.org/10.1590/0037-86820030-2014.

19. Kupek E, Oliveira JFd. Transmissão vertical do HIV, da sífilis e da hepatite B no município de maior incidência de AIDS no Brasil: um estudo populacional no período de 2002 a 2007. Revista Brasileira de Epidemiologia. 2012 Sep; 15( 3 ): 478-487. http://dx.doi.org/10.1590/S1415790X2012000300004.

20. Saraceni V, Pereira GFM, da Silveira MF, Araujo MAL, Miranda AE. Vigilância epidemiológica da transmissão vertical da sífilis: dados de seis unidades federativas no Brasil. Revista Panamericana de Salud Pública. 2017 Jun 8;41:e44. Portuguese. doi: 10.26633/RPSP.2017.44.

21. Taylor MM, Nurse-Findlay S, Zhang X, Hedman L, Kamb ML, Broutet N, et al. Estimating Benzathine Penicillin Need for the Treatment of Pregnant Women Diagnosed with Syphilis during Antenatal Care in High-Morbidity Countries. PLoS One. 2016;11(7):e0159483. Epub 2016/07/21. doi: 10.1371/journal.pone.0159483.

22. Clement ME, Okeke NL, Hicks CB. Treatment of syphilis: a systematic review. Jama. 2014;312(18):1905-17. Epub 2014/11/12. doi: 10.1001/jama.2014.13259.

\section{Figures}



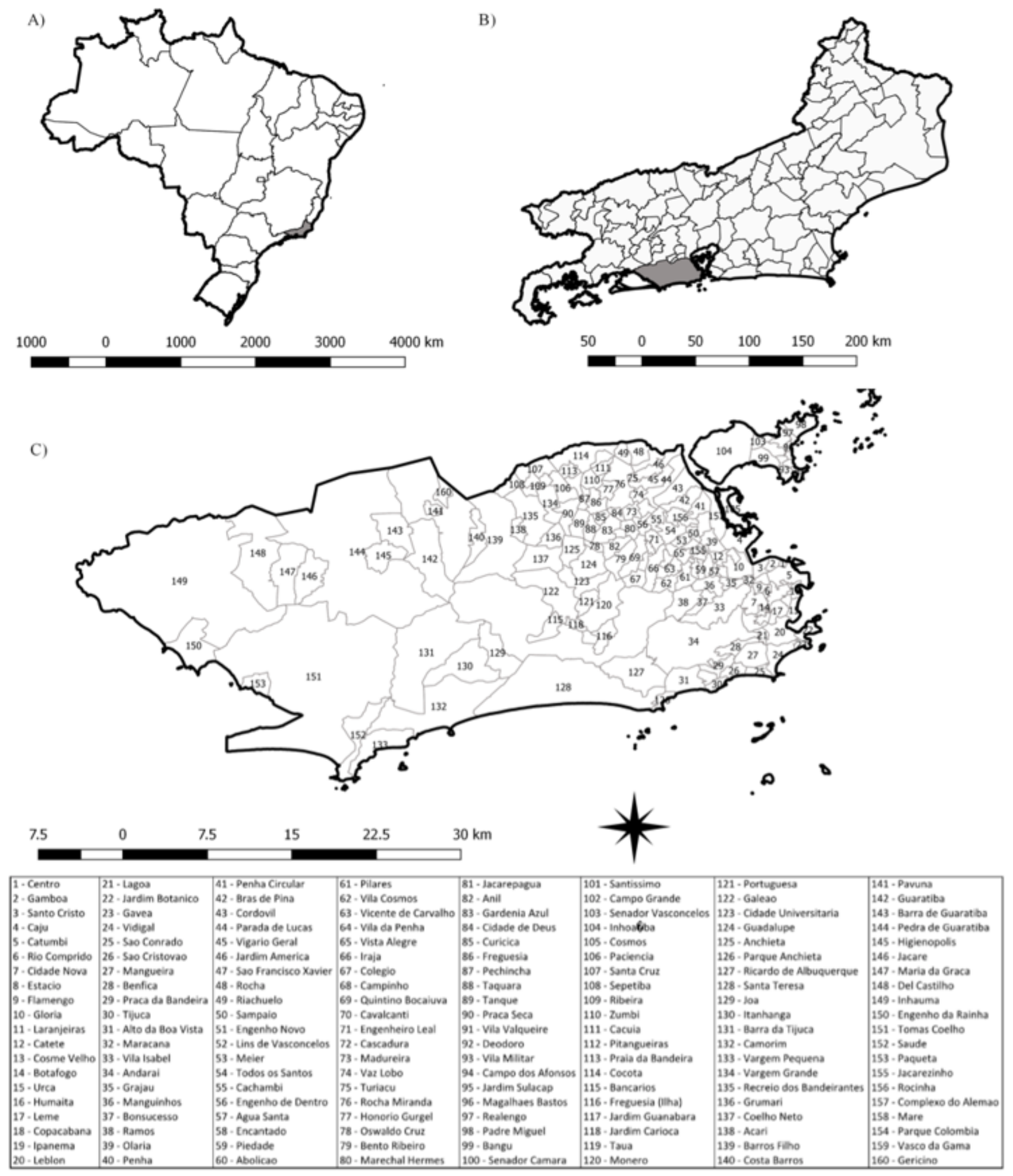

\section{Figure 1}

Localization of the study area: A) Brazil map with Federate units, B) Rio de Janeiro state with municipalities, C) Neighborhoods of the city of Rio de Janeiro 


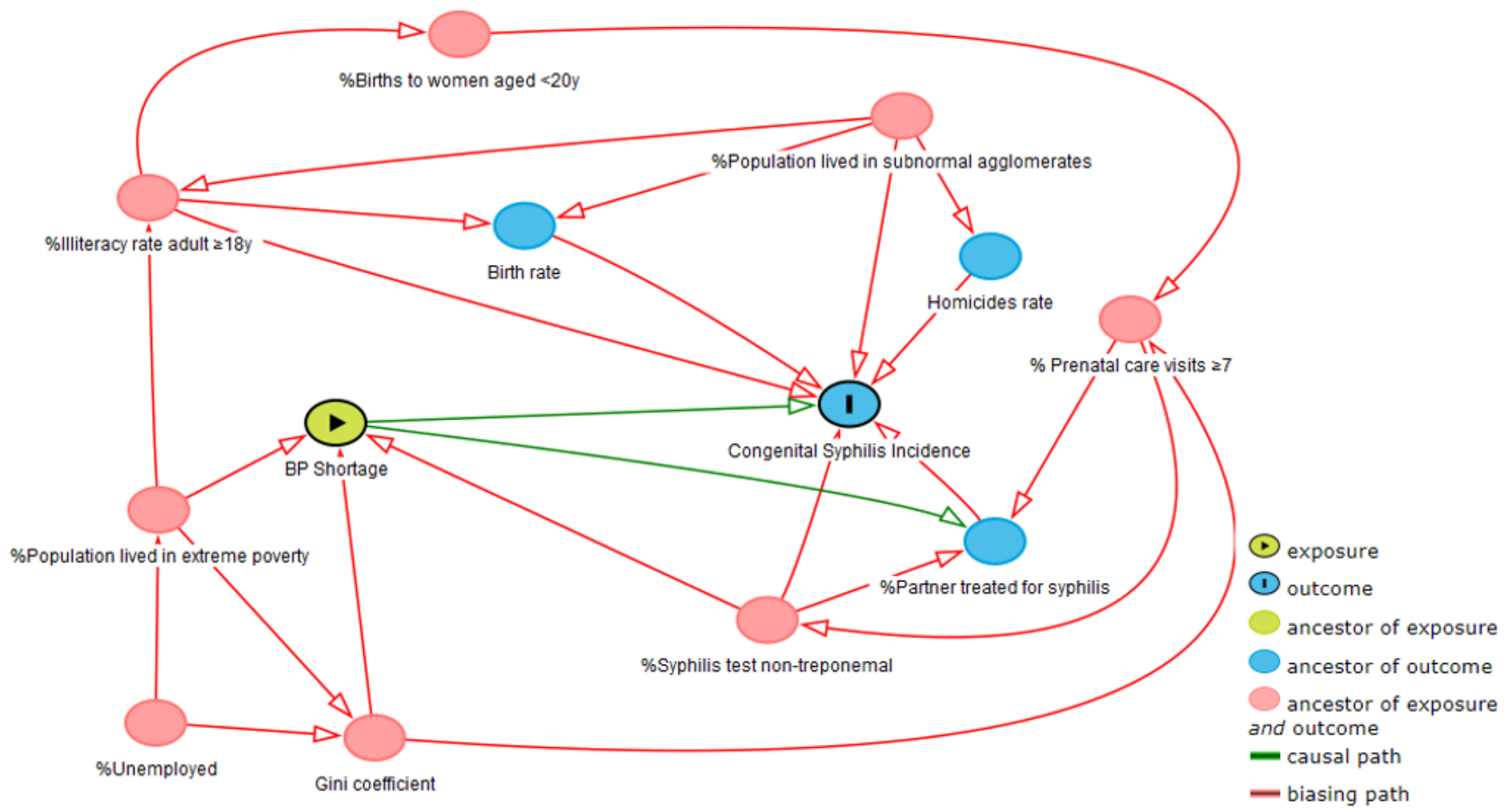

Figure 2

Directed acyclic graph of the significant increase in Congenital Syphilis incidence, Benzathine Penicillin shortage, and associated covariates
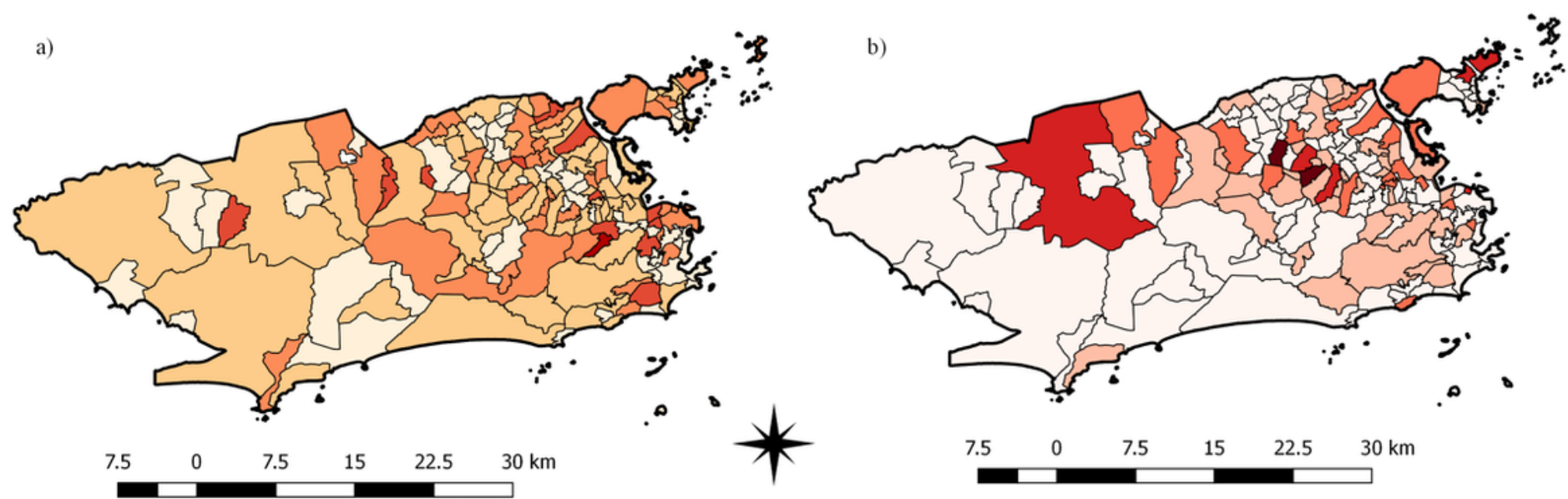

Congenital Syphilis Incidence

Increment of at least $200 \%$ in Congenital Syphilis Incidence

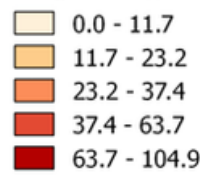

$\square 0$
$\square 1$
$\square 2$
$\square 3$
$\square$

\section{Figure 3}


Spatial distribution of Syphilis: A) Congenital Syphilis Incidence Rate map and B) Map of neighborhoods with increase of at least 200\% in the incidence of Congenital Syphilis, Rio de Janeiro 2013-2017 